\title{
Community nutrition in Spain: advances and drawbacks
}

\author{
Javier Aranceta, Felix Lobo, Pilar Viedma, Gemma Salvador-Castell, Emilio Martínez de Victoria, \\ Rosa M Ortega, Luis Bello, and Josep A Tur-Marí
}

\begin{abstract}
Scientific evidence has placed community nutrition among the front-line strategies in health promotion. Community nutrition in different regions of Spain has developed at an unequal pace. Early initiatives in the mid 1980s provided good-quality population data and established a basis for nutrition surveillance including individual body measurements, dietary intake data, information on physical activity, and biomarkers. The Nutrition and Physical Activity for Obesity Prevention Strategy (NAOS) reinforces community nutrition action in Spain. Presented here is an overview of developments in community nutrition in Spain in recent years as well as potential trends under the scope of the NAOS.
\end{abstract}

\section{INTRODUCTION}

A growing body of scientific and epidemiological evidence supports the association between different aspects of diet and health, either as risk factors or as providers of beneficial or protective effects in relation to major chronic diseases. ${ }^{1}$ This has led to research focusing on qualitative dietary patterns that may have an impact on the development of chronic diseases, quality of life, physical and cognitive capabilities, and longevity, the results of which have a consequent effect on the development of community nutrition. ${ }^{2,3}$

The main functions of a community nutrition unit consist of the identification and assessment of prevailing nutritional problems in the community as determined via needs assessments. Other key functions include the design, planning, organizing, implementation, monitoring, and evaluation of nutrition intervention programs in different settings, such as the workplace, schools, the general population, or in at-risk groups. ${ }^{4,5}$ Community interventions aim to gradually progress towards healthier dietary patterns in the population. The selection of the most suitable strategies should be evidence based, considering the target groups, social and cultural context, and available resources. ${ }^{6}$ Community nutrition programs usually require a simultaneous combination of different approaches and strategies guided by a multidisciplinary team (Figure 1).

The Community Nutrition Unit of the Bilbao Department of Public Health was created in 1984. It constituted the first initiative of its kind in Spain. Since then, a number of research and working groups have emerged in the field of community nutrition, acting at the local or regional levels. Catalonia, the Canary Islands, the Region of Madrid, Valencia, the Balearic Islands, Andalusia, and Galicia are Spanish regions where remarkable community nutrition projects and initiatives have been developed and implemented in the last 20 years. The unequal development of community nutrition in Spain is mainly due to the different perceptions and political support from the regional and local governments.

It is hoped that the development and implementation of the Nutrition and Physical Activity for Obesity Prevention Strategy (NAOS) and satellite programs 


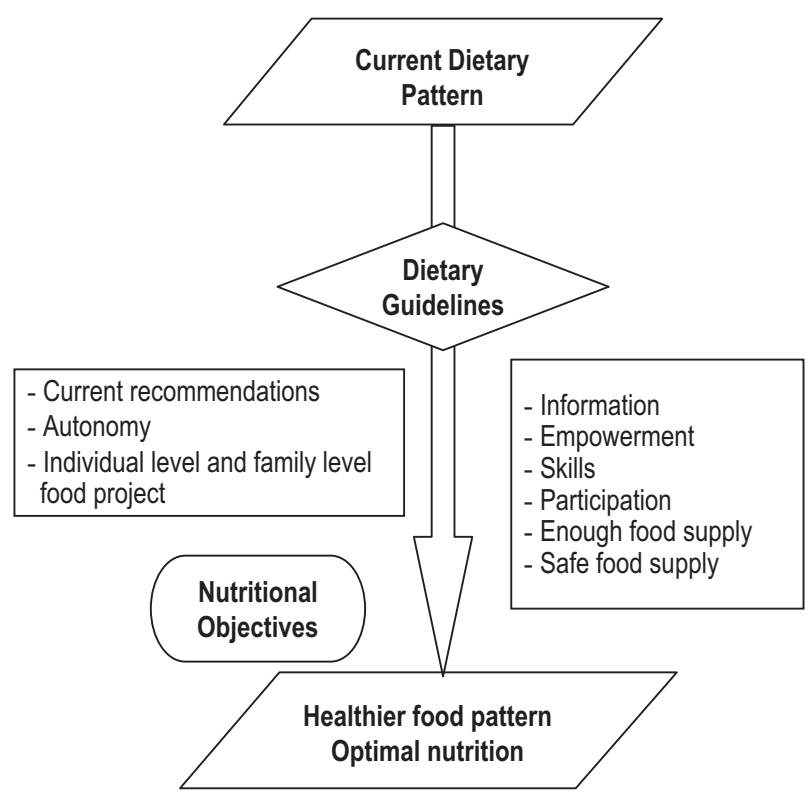

Figure 1 Concept model for community nutrition.

launched by the Spanish Ministry of Health will provide a new impulse to action in the area of public health nutrition in municipalities acting at the local level, the regional level, and directed towards the entire population of the country. ${ }^{7}$

\section{REGIONAL EXPERIENCES IN COMMUNITY NUTRITION}

To date, nutrition surveillance at the country level is mostly based on food disappearance data, ${ }^{8}$ household budgetary surveys, ${ }^{9}$ and the National Health Survey, ${ }^{10}$ which includes self reported weight and height. At the national level, no formal nutrition surveillance system has been established to date that includes ongoing data collection of individual body measurements, dietary intake assessment, physical activity, and biochemical markers.

However, developments at the regional level in the mid-1980s were oriented towards the nutritional assessment of the population and contributed to gaining insight into the problem. The mapping of the prevalence of obesity in different population groups and analysis of trends over time is one of the valuable outcomes of such initiatives. ${ }^{11,12}$ Autonomous regions such as the Basque Country, ${ }^{13}$ Catalonia, ${ }^{14}$ the Canary Islands, ${ }^{15}$ Madrid, ${ }^{16}$ Andalucia, ${ }^{17}$ the Balearic Islands, ${ }^{18}$ and Valencia ${ }^{19}$ carried out nutrition surveys on random population samples using similar protocols, thus enabling the comparison or even pooling of data for analysis. ${ }^{20}$ In some cases, more than one survey has been performed, allowing trend analysis to be conducted.

Comparison of results from the 2001 and 2005 National Health Surveys in the region of Valencia shows a decrease in the consumption of meat and meat products and an increase in the consumption of fish. Consumption of baked goods and cakes decreased, and a reduced consumption of fruits and vegetables was observed.

According to the 2005 data, at 4 weeks after birth, $58.2 \%$ of the newborns were breastfed. At 3 months, the proportion was $42.35 \%$ and by month $6,25.6 \%$ were breastfed. ${ }^{21}$

The Health Plan for the Autonomous Region of Valencia 2005-2009 considers the promotion of healthier diets and physical activity among the main objectives. Development and implementation of health education programs focused on healthier eating practices are among the specific objectives, which include 13 lines of action at the family, school, and local levels.

The Food and Nutrition Programme at the Department of Health in Catalonia was founded in 1985. In the early stages, setting up a nutrition surveillance system was one of the priorities to guide the definition of nutritional health policy for the community. Three population nutrition surveys have been carried out so far, in 1987, 1992, and 2003. Community action undertaken after the first survey included awareness campaigns, educational materials for schoolchildren, and media-based actions, such as specific newspaper and radio programs. Additionally, continuing education seminars for primary healthcare professionals were arranged and dietary protocols for primary healthcare were developed. ${ }^{22}$ Other actions included a program targeting school meals. More recently, in line with the NAOS, a regional action plan (PAAS) has been developed to promote healthier eating practices and physical activity in the population.

Similar developments have taken place in other autonomous regions in Spain, such as Madrid, Andalusia, the Balearic Islands, and the Canary Islands. The actions implemented have placed a particular focus on school meal programs, school nutrition education, consumer information, and continuing education initiatives for primary healthcare professionals.

Data from the Canary Islands show that, despite the fact that nutrition-related diseases have accounted for more than $50 \%$ of deaths in the region since 1975 , to date, only $6.5 \%$ of the regional health budget is invested for their early intervention and prevention.

\section{THE NAOS STRATEGY: FIRST YEAR REPORT}

Available epidemiological data on the prevalence and trends of obesity in many countries, ${ }^{23,24}$ as well as the negative impact on health, ${ }^{25-28}$ contributed to the development and approval of the WHO Global Strategy on Diet and Physical Activity in 2004. ${ }^{29}$ This initiative encouraged all member states to develop and implement national action plans and strategies aimed at fostering 
healthier eating practices and physical activity in the population, with a particular emphasis on children and young people.

The Spanish Ministry of Health is aware of the urgent need for action in the country. An obesity epidemic has developed over the last two decades in Spain, and it will take at least one more decade to reverse the trend. Achieving this requires initiatives based on individual responsibility as well as actions addressing the social, economic, and cultural environments. Strategies to combat the problem should be aimed at the adoption of healthier eating habits and an active lifestyle through nutrition education of the public and political action leading to easier access to healthy options. ${ }^{30,31}$ Such actions must be targeted towards all age groups, but a special emphasis should be placed on the younger generations, i.e., children and adolescents. These interventions need to be integrated and combine actions in the school setting, family environments, workplaces, and municipalities. Evidence should guide the selection of the most effective and suitable strategies for intervention. ${ }^{32,33}$ Potential partnerships and collaboration between the private and the public sectors should not be dismissed. A careful plan for monitoring and evaluating the developments is required to gain effectiveness. ${ }^{34}$

The philosophy behind the NAOS strategy is positive. The focus is placed on recommendations for what to do rather than stigmatizing or encouraging negative messages based on prohibition and limitation. It is also participative; it emphasizes networking and involves all sectors and stakeholders in the social and economic domains. All of them are partners in a global strategy. It is proactive; each actor adopts their own commitments to contribute to the overall goal of the national strategy. ${ }^{35}$

The key objectives of the NAOS Strategy are as follows: to increase public awareness about the positive impact of a balanced diet and physical activity for health; to develop policies and action plans to foster healthier lifestyles; to favor a framework for collaboration with the food industry to modify the composition of certain food products and to develop healthier products; to promote and support the systematic early detection of overweight and obese individuals within the National Health System; and to monitor the actions adopted and evaluate achieved results.

Several working groups were constituted to develop the NAOS strategy, namely: 1) healthy physical activity, nutritional objectives, and dietary guidelines; 2 ) education to overcome obesity; 3) environmental determinants of obesity; 4) genetic determinants of obesity; 5) healthcare determinants of obesity - prevention, diagnosis and treatment, 6) information systems and epidemiology; and 7) research.
Among several achievements during the first year of the NAOS strategy, it is worth mentioning the PERSEO program and the self-regulation code of food publicity aimed at minors (PAOS code). PERSEO is a school-based program launched jointly by the Spanish Ministry of Health and the Spanish Ministry of Education with the overall aim of creating a school and family environment supportive of healthier eating habits and physical activity among primary school children. PERSEO focuses on increased consumption of fruits and vegetables, decreased consumption of fat, increased physical activity levels, and decreased sedentary habits both in school and out of school. ${ }^{36}$ It also aims to favor early identification and to avoid progression of overweight in children as well as to create simple indicators to monitor progress and evaluate changes. Active partners include the Spanish Agency for Food Safety and Nutrition, the Center for Innovation and Education Development, parent associations, the Spanish Federation of Municipalities, regional departments of health and education, schools, and primary healthcare professionals. Other measures already in place include changes in food labels and information provided to consumers and the PAOS code. The PAOS code aims to protect children younger than 12 years of age from the excess pressure brought on by marketing of foods and beverages. Thirty-five principal Spanish food companies have already signed the agreement. Collectively, they represent more than $75 \%$ of the investment in food marketing.

It is supervised by an autonomous body, which regulates the marketing of participating enterprises. The autonomous body is comprised of delegates from the Spanish Agency for Food Safety and Nutrition (AESAN), delegates from the Spanish Federation of Food and Beverage Industries (FIAB), delegates from the Spanish Council of Consumers and Users, and a delegate from the Self-Advertising Control Commission with no voting right. A preview control system has been set up for all advertisements and TV commercials targeted to children, particularly for those to be broadcasted during the time interval established for children's programs. Financial penalties that are applied for violation range from $€ 6,000$ to $€ 180,000$. $^{37}$

During the first 15 months of implementation (between 15 September 2005 and 31 December 2006), a total of 582 commercials, most of them television announcements, were analyzed prior to broadcasting. Close to three-quarters (73\%) of them were approved. Changes were recommended in 118 cases and in 40 more cases negative feedback was provided for not being in agreement with the PAOS code and the advertisements could not be broadcast. The main reasons for modification requests were noncompliance with Regulation 18, which deals with the unclear specification of special 
promotions (60 commercials), and noncompliance with Regulation 13, which addresses the presence of wellknown celebrities in the commercial (47 additional commercials). Between February 2005 and February 2006 there was a $60 \%$ decrease in the number of television commercials advertising foods or beverages targeted to children and involving popular celebrities.

The prevention and treatment of obesity has been included among the list of services provided by the National Health Care system and plans for obesity prevention are included as part of the Plan for Quality Assurance of the National Health Care System.

\section{CONCLUSION}

The NAOS strategy reinforces community nutrition action in Spain. Up until its implementation, most development had taken place at the regional and local levels. For the first time, there is a national action plan in Spain with a principal focus on nutrition and physical activity within a public health context. Multifaceted integrated actions backed by strong political commitment for environmental changes are essential. However, support for actions at the local level leads the change. Monitoring and evaluation will continue to report achievements and build on the cost-effectiveness of the investment.

\section{Acknowledgment}

Declaration of interest. The authors have no relevant interests to declare.

\section{REFERENCES}

1. World Health Organization. Diet, nutrition and the prevention of chronic diseases. Report of a Joint FAO/WHO Expert consultation. WHO Technical Report Series 916. Geneva: WHO; 2003.

2. Pomerleau J, McKee M, Lobstein T, Knai C. The burden of disease attributable to nutrition in Europe. Public Health Nutr. 2003;6:453-462.

3. Kant AK, Schatzkin A, Graubard BI, Schairer C. A prospective study of diet quality and mortality in women. JAMA. 2000;283:2109-2115.

4. Hughes R. A conceptual framework for intelligence-based public health nutrition workforce development. Public Health Nutr. 2003;6:599-606.

5. Aranceta Bartrina J. Community nutrition. Eur J Clin Nutr. 2003;57(Suppl 1):S79-S81.

6. Boyle MA, Morris DH. Community Nutrition in Action, an Entrepreneurial Approach. (Second edition). Belmont, CA: West/ Wadsworth ITP Inc.; 1999.

7. AESAN. Spanish Strategy for Nutrition, Physical Activity and the Prevention of Obesity (NAOS). Madrid: Ministry of Health and Consumer Affairs; 2004.

8. Ministerio de Agricultura, Pesca y Alimentación. La alimentación en España 2004. Madrid: Ministerio de Agricultura, Pesca y Alimentación; 2005.
9. Varela G, Moreiras O, Carbajal A, Campo M. Encuesta de Presupuestos Familiares 1990-91. Estudio Nacional de Nutrición y Alimentación 1991. Tomo I. Madrid: INE; 1995.

10. Ministerio de Salud y Consumo. Encuesta Nacional de Salud (ENS). Available at: http://ww1.msc.es/salud/epidemiologia/ ies/encuesta2001/encuesta.htm. Accessed 1 June 2007.

11. Aranceta Bartrina J, Serra Majem LL, Foz Sala M, Moreno Esteban B, Grupo Colaborativo SEEDO. Prevalence of obesity in Spain. Med Clin (Barc). 2005;125:460466.

12. Aranceta J, Pérez-Rodrigo C, Serra-Majem LL, et al. Influence of sociodemographic factors in the prevalence of obesity in Spain. The SEEDO'97 Study. Eur J Clin Nutr. 2001;55:430435.

13. Aranceta J, Perez Rodrigo C, Eguileor I, Marzana I, Gonzalez de Galdeano L, Saenz de Buruaga J. Food consumption patterns in the adult population of the Basque Country (EINUT-I). Public Health Nutr. 1998;1:185-189.

14. Serra Majem L, Ribas Barba L, García Closas R, et al. Avaluació de l'estat nutricional de la població catalana (1992-93). Avaluació dels hàbits alimentaris, el consum d'aliments, energia $i$ nutrients, i de l'estat nutricional mitjançant indicadors bioquímics i antropomètrics. Barcelona: Generalitat de Catalunya, Departament de Sanitat i Seguretat Social; 1996.

15. Serra Majem L, Cabrera Leon A, Sierra Lopez A. Conclusiones de la Encuesta de Nutrición de Canarias (1997-98). Bases para una política de nutrición en Canarias. Arch Latinoam Nutr. 2000;50(Suppl 1):S62-S70.

16. Aranceta J, Pérez C, Amela C, García R. Encuesta de Nutrición de la Comunidad de Madrid. Documentos Técnicos de Salud Pública ${ }^{\circ}$ 18. Madrid: Dirección General de Prevención y Promoción de la Salud, Comunidad de Madrid; 1994.

17. Mataix Verdú J, Llopis González J, Martínez de Victoria E, Montellano Delgado MA, López Frias M, Aranda Ramírez P. Valoración del estado nutricional de la Comunidad Autónoma de Andalucía. Granada: Dirección General de Salud Pública y Participación de la Junta de Andalucía, Instituto de Nutrición y Tecnología de Alimentos de la Universidad de Granada, Escuela Andaluza de Salud Pública; 1999.

18. Tur JA, Obrador A (dirs). Estudio de Nutrición de las Islas Baleares. ENIB, 1999-2000. Libro blanco de la alimentación y la nutrición en las Islas Baleares. Volumen I. Rev Cien IEB. 2002;27:1-120.

19. Vioque J, Quiles J. Encuesta de nutrición y salud de la Comunidad Valenciana, 1994. Alicante: Departamento de Salud Pública- Universidad Miguel Hernández; 2003.

20. Ortega RM, Aranceta J, Serra-Majem L, Entrala A, Gil A, Mena MC. Nutritional risks in the Spanish population: results of the eVe study. Eur J Clin Nutr. 2003;57(Suppl 1):S73-S75.

21. Department of Health. Generalitat Valenciana. Encuesta de Salud de la Comunidad Valenciana (año 2005). Available at: http://www.san.gva.es/cas/ciud/homeciud.html. Accessed 10 September 2007.

22. Departament de Sanitat i Seguretat Social. Generalitat de Catalunya. Protocols dietètics per a l'atenció primària. Departament de Sanitat i Seguretat Social. Barcelona: Generalitat de Catalunya; 1992.

23. Lobstein T, Baur L, Uauy R. Obesity in children and young people: a crisis in public health. IASO International Obesity Task Force. Obes Rev. 2004;5(Suppl 1):S4-S85.

24. International Obesity Task Force. The global challenge of obesity and the International Obesity Task Force. International Obesity Task Force, London - January 2007. Available 
at: $\quad$ http://www.iuns.org/features/obesity/tabfig.htm. Accessed 10 September 2007.

25. Reilly JJ, Methven E, McDowell ZC, et al. Health consequences of obesity. Arch Dis Child. 2003;88:748-752.

26. Wang G, Dietz WH. Economic burden of obesity in youths aged 6 to 17 years: 1979-1999. Pediatrics. 2002;109:E81-1.

27. Fontaine KR, Redden DT, Wang C, Westfall AO, Allison DB. Years of life lost due to obesity. JAMA. 2003;289:187193.

28. Calle EE, Teras LR, Thun MJ. Obesity and mortality. N Engl J Med. 2005;353:2197-2199.

29. World Health Organization. Global Strategy on Diet, Physical Activity and Health. Resolution WHA57.17. Geneva: World Health Organization; 2004.

30. Swinburn $B$, Egger $G$. The runaway weight gain train: too many accelerators, not enough brakes. BMJ. 2004;329:736739.

31. Lang T, Rayner G. Overcoming policy cacophony on obesity: an ecological public health framework for policymakers. Obes Rev. 2007;8(Suppl 1):S165-S181.
32. Doak CM, Visscher TLS, Renders CM, Seidell JC. The prevention of overweight and obesity in children and adolescents: a review of interventions and programmes. Obes Rev. 2006;7:111-136.

33. Summerbell $C D$, Waters $E$, Edmunds $L D$, Brown $T$, Campbell KJ. Interventions for preventing obesity in children. Cochrane Libr. 2006;(3):CD001871.

34. World Health Organization. Framework and Indicators for DPAS. Geneva: WHO; 2005.

35. Neira M, de Onis M. The Spanish strategy for nutrition, physical activity and the prevention of obesity. $\mathrm{Br} J$ Nutr. 2006;96(Suppl 1):S8-S11.

36. Expert Committee - AESAN. The PERSEO program. Available at: http://www.perseo.aesan.msc.es/es/programa/ programa_perseo.shtml. Accessed 30 March 2009.

37. Expert Committee - AESAN. The PAOS code. Available at: http://www.naos.aesan.msc.es/naos/empresas/publicidad/. Accessed 30 March 2009. 